Proceedings of the XXIII Conference on Applied Crystallography, Krynica Zdrój, Poland, September 20-24, 2015

\title{
Martensite Reorientation after Thermal Cycling in NiTiCu Shape Memory Alloys Studied by EBSD Technique
}

\author{
J. RAK ${ }^{a, *}$, T. GORYCZKA ${ }^{a}$ AND P. OCHIN ${ }^{b}$ \\ ${ }^{a}$ Institute of Materials Science, University of Silesia, 75 Pułku Piechoty 1A, 41-500 Chorzów, Poland \\ ${ }^{b}$ CNRS-ICMPE, 2 rue Henri Dunant, 94320, Thiais, France
}

\begin{abstract}
The $\mathrm{Ni}_{25} \mathrm{Ti}_{50} \mathrm{Cu}_{25}$ shape memory alloy exhibits one-step martensitic transformation. Transformation occurs between the $B 2$ parent phase and the $B 19$ orthorhombic martensite. The course of the martensitic transformation was in situ studied in the alloy with use of electron backscatter diffraction. During heating, reverse martensitic transformation occurs from the $B 19$ orthorhombic martensite to the $B 2$ parent phase. On cooling, from the parent phase the $B 19$ martensite is formed. Obtained results proved that the $B 19$ martensitic plates forms the variants indexed as 1,3 , and 5 . Thermal cycling does not change the crystallographic correlation between the parent phase and the martensite. However, after cycling, different rearrangement of the martensitic plates can be received. In consequence, characteristic temperatures of the martensitic transformation are shifted.
\end{abstract}

DOI: 10.12693/APhysPolA.130.1075

PACS/topics: $62.20 . \mathrm{fg}, 68.37 . \mathrm{Hk}$

\section{Introduction}

$\mathrm{NiTiCu}$ alloys obtained by replacing a part of $\mathrm{Ni}$ atoms by $\mathrm{Cu}$ in the equiatomic NiTi alloy have attracted wide interest because of a variety of advantages in practical use. Copper addition, as a ternary alloying element, results in increase of the characteristic temperatures of the martensitic transformation, when compared to a binary NiTi alloy [1,2]. In the $\mathrm{Ni}_{25} \mathrm{Ti}_{50} \mathrm{Cu}_{25}$ shape memory alloy, martensitic transformation occurs by a one step with the sequence $B 2 \leftrightarrow B 19$. The crystallographic lattices of the both phases are strictly correlated. During transformation one lattice is transformed into other via habitus plane. In consequence of that different variants of the martensitic plates can be formed $[3,4]$. Crystallographic orientation of the parent phase or the martensite plays a key role in the shape memory effect. Dependently on that, from 1 up to $6 \%$ of elongation can be received [5].

The present work shows results of in situ studies done on a course of the martensitic transformation, which occurs in $\mathrm{Ni}_{25} \mathrm{Ti}_{50} \mathrm{Cu}_{25}$ shape memory alloy. The martensitic transformation was induced by the change of temperature.

\section{Experimental}

The NiTiCu shape memory alloy with a chemical composition of $\mathrm{Ni}_{25} \mathrm{Ti}_{50} \mathrm{Cu}_{25}$ (at.\%) was produced with use of the melt-spinning technique [6-8]. Alloy was cast from $1352^{\circ} \mathrm{C}$ and wheel speed was $19 \mathrm{~m} / \mathrm{s}$. As-cast ribbon was about $1 \mathrm{~cm}$ wide and about $30 \mu \mathrm{m}$ thick. The ribbon was in a semi-polycrystalline state. In order to receive completely crystalline alloy, samples were thermally treated at $500^{\circ} \mathrm{C}$ for $2 \mathrm{~min}$ in a vacuum furnace $\left(10^{-6} \mathrm{hPa}\right)$.

\footnotetext{
*corresponding author; e-mail: jan.rak@us.edu.pl
}

Thermal behavior of the martensitic transformation was studied with use of differential scanning calorimeter (DSC) Mettler Toledo DSC-1. Transformation temperatures of the martensitic transformation were determined from the thermograms measured with a heating/cooling rate of $10^{\circ} \mathrm{C} / \mathrm{min}$ over a thermal range from $20^{\circ} \mathrm{C}$ to $100^{\circ} \mathrm{C}$.

Microstructure of the ribbon was observed using an electron scanning microscope JEOL SEM 6480 equipped with an EBSD detector. In order to measure the grain orientation versus temperature change a heating attachment was used. Attachment enables for temperature control and its change in the thermal range between room temperature (RT) and $700^{\circ} \mathrm{C}$.

\section{Results and discussion}

The ribbon reveals a presence of the reversible martensitic transformation. Figure 1 shows DSC cooling/heating curves, in which only one maximum and one minimum appeared during cooling and heating, respectively. During heating, low temperature phase (the orthorhombic $B 19$ martensite) transforms to the high temperature $B 2$ parent phase. The characteristic start temperature of this transformation is equal to $69.8^{\circ} \mathrm{C}\left(A_{s}\right)$. The reverse transformation is completed at $78.2^{\circ} \mathrm{C}\left(A_{f}\right)$. In opposition to that, forward transformation proceeds from the $B 2$ parent phase and starts at $69.7^{\circ} \mathrm{C}\left(M_{s}\right)$. This transformation is completed at $60.1^{\circ} \mathrm{C}\left(M_{f}\right)$. Below the $M_{f}$ temperature only martensite exists. Thermal cycling of the martensitic transformation causes shift of the characteristic temperatures between first and second cycle (lowering of $A_{s}$ and $A_{f}$ temperatures), in subsequent cycles temperatures are stabilizing (Table I).

Course of the martensitic transformation was observed with the use of scanning electron microscopy (SEM) during sample cooling as well as heating. Distribution of 


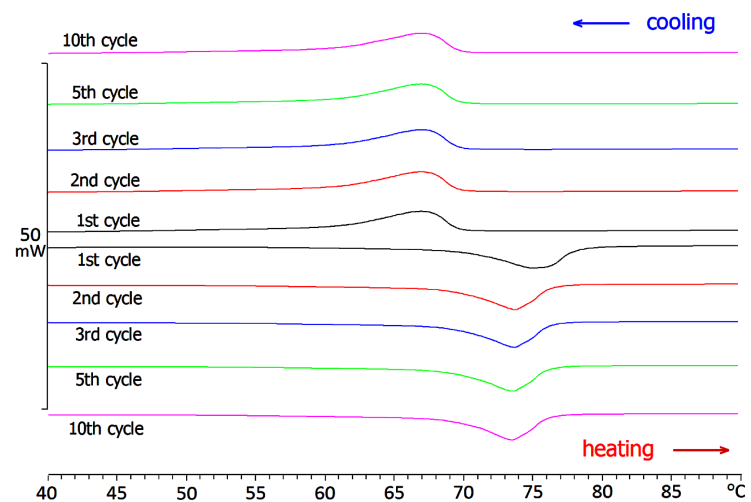

Fig. 1. DSC cooling/heating curves measured for $\mathrm{Ni}_{25} \mathrm{Ti}_{50} \mathrm{Cu}_{25}$ shape memory alloy after cycling.

TABLE I

Characteristic temperatures measured for investigated $\mathrm{Ni}_{25} \mathrm{Ti}_{50} \mathrm{Cu}_{25}$ shape memory alloy after cycling.

\begin{tabular}{c|c|c|c|c|c|c}
\hline \hline \multirow{2}{*}{ Cycle } & $M_{s}$ & $M_{f}$ & $\Delta Q_{M}$ & $A_{s}$ & $A_{f}$ & $\Delta Q_{A}$ \\
\cline { 2 - 7 } & \multicolumn{2}{|c|}{$\left[{ }^{\circ} \mathrm{C}\right]$} & {$[\mathrm{J} / \mathrm{g}]$} & \multicolumn{2}{|c}{$\left[{ }^{\circ} \mathrm{C}\right]$} & {$[\mathrm{J} / \mathrm{g}]$} \\
\hline 1 & 69.7 & 60.1 & 13.4 & 69.8 & 78.2 & 13.1 \\
2 & 69.7 & 60.3 & 13.4 & 68.7 & 76.5 & 13.4 \\
3 & 69.7 & 60.2 & 13.4 & 68.9 & 76.4 & 13.3 \\
5 & 69.7 & 60.1 & 13.8 & 68.8 & 76.3 & 13.5 \\
10 & 69.8 & 59.9 & 13.8 & 68.9 & 76.2 & 13.4
\end{tabular}

grains, formed during rapid solidification, is shown in orientation contrast images (Fig. 2). Observed images are representative to the whole surface of the alloys. SEM image observed at room temperature reveals presence of the $B 19$ martensitic plates (Fig. 2a), which were formed inside of grains. Further sample heating (up to $76^{\circ} \mathrm{C}$ ) causes vanishing of the rest of the $B 19$ phase. At that temperature, the ribbon was completely transformed to the $B 2$ phase (Fig. 2b)

Whole observed regions consisted of the $B 2$ grains. Sample cooling down to the room temperature again caused formation of the martensitic plates (Fig. 2c). However, distribution of the martensite planes was different from that, which was observed at the initial state of the ribbon.

In order to study crystallographic correlation between both transformed phases and between martensite plates, the electron back scattered diffraction (EBSD) patterns were analyzed. First, measurements were done at room temperature, for the primary martensitic state. Next, it was done for the parent phase at $76^{\circ} \mathrm{C}$. Finally, orientation maps were stored at the room temperature for the martensite, which was formed after first thermal cycle.

In $\mathrm{Ni}_{25} \mathrm{Ti}_{50} \mathrm{Cu}_{25}$ shape memory alloy, the martensitic transformation occurs between the $B 2$ - cubic crystal lattice and the $B 19$ martensite - orthorhombic crystal lattice. Between both lattices exists a crystallographic correlation. In consequence, any atom, crystallographic direction or plane, from one phase can be
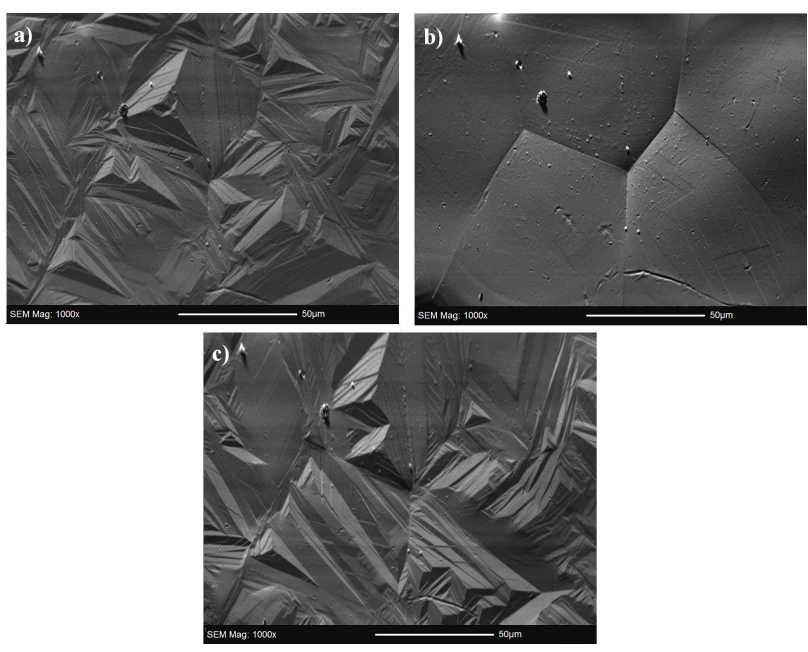

Fig. 2. Orientation contrast images of the ribbon observed at temperature: room temperature (a), $76^{\circ} \mathrm{C}(\mathrm{b})$, and after cooling down to room temperature (c).

transformed to another. Between the $B 2$ parent phase and the orthorhombic martensite exists only six crystallographic lattice relations - called martensite variants [9]. In order to compensate grain deformation, induced during transformation, the martensite variants are twin-related. Watanabe defined the martensite variants in the $B 2 \leftrightarrow B 19$ transformation and showed their crystallographic correlations (Table II) [10].

TABLE II

Crystallographic relation between lattices of the $B 2$ parent phase and the $B 19$ martensite [10].

\begin{tabular}{c|c|c|c}
\hline \hline Variant & {$[100]_{B 19}$} & {$[010]_{B 19}$} & {$[001]_{B 19}$} \\
\hline 1 & {$[100]_{B 2}$} & {$[011]_{B 2}$} & {$[0 \overline{1} 1]_{B 2}$} \\
\hline 2 & {$[100]_{B 2}$} & {$[0 \overline{1} 1]_{B 2}$} & {$[0 \overline{1} \overline{1}]_{B 2}$} \\
\hline 3 & {$[010]_{B 2}$} & {$[101]_{B 2}$} & {$[10 \overline{1}]_{B 2}$} \\
\hline 4 & {$[010]_{B 2}$} & {$[10 \overline{1}]_{B 2}$} & {$[\overline{1} 0 \overline{1}]_{B 2}$} \\
\hline 5 & {$[001]_{B 2}$} & {$[110]_{B 2}$} & {$[\overline{1} 10]_{B 2}$} \\
\hline 6 & {$[001]_{B 2}$} & {$[1 \overline{1} 0]_{B 2}$} & {$[\overline{1} \overline{1} 0]_{B 2}$}
\end{tabular}

In orientation maps (Fig. $3 \mathrm{a}-\mathrm{c}$ ) for the analysis of the lattices correlation and variants of the martensite plates, in studied $\mathrm{Ni}_{25} \mathrm{Ti}_{50} \mathrm{Cu}_{25}$ ribbon, the grain I and II (Fig. $3 \mathrm{~b})$ was chosen. In general, stereographic projection reveals that orientation of the grain is close to (100)[001] sheet texture indexed in the $B 2$ lattice. It means that crystallographic plane $(100)_{B 2}$ is parallel to surface of the ribbon. Consequently, crystallographic direction $[001]_{B 2}$ is perpendicular to its surface.

Going into details of the lattices correspondences, it can be seen that stereographic projections of the grain (in the $B 2$ phase) is a sum of the separate martensite plates orientation, which was determined for primary B19 martensite as well as for the B19 martensite formed after sample cooling from $76^{\circ} \mathrm{C}$. Further, from 

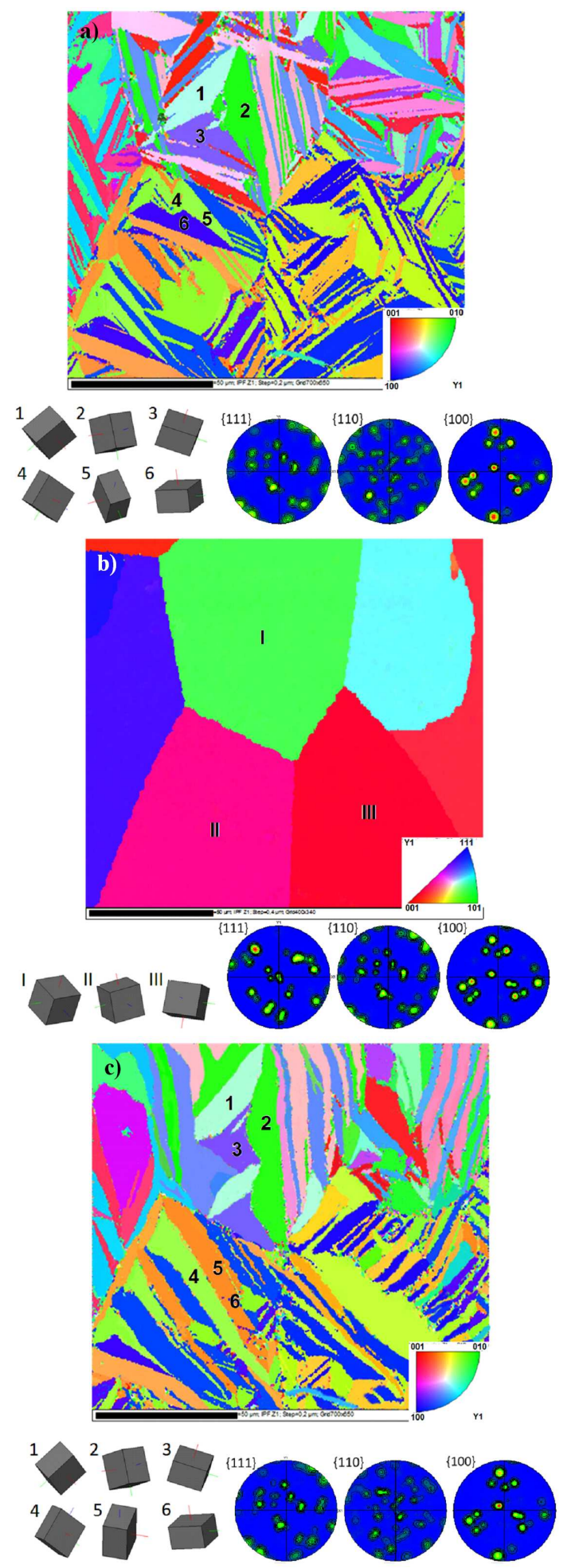

Fig. 3. Orientation maps measured at room temperature: $B 19$ structure (a), after heating to $76^{\circ} \mathrm{C}-B 2$ structure (b), after cooling down to RT $-B 19$ structure (c) with crystal lattice of plates marked as 1-6 (a,c) and crystal lattice of the grains marked as I-III (b) with stereographic projections $(\mathrm{a}-\mathrm{c})$. comparison of crystal lattices orientation and the stereographic projections done for primary martensite (room temperature) and the $B 2$ phase (temperature $76^{\circ} \mathrm{C}$ ) it can be drawn that some basic crystallographic directions are parallel. Following lattice correlations can be found between orientation of martensite plates and the parent phase:

plate " $A$ ":

$[100]_{B 19}\left\|[001]_{B 2} ;[010]_{B 19}\right\|[110]_{B 2} ;[001]_{B 19} \|[\overline{1} 10]_{B 2}$ plate " $B$ ":

$[100]_{B 19}\left\|[010]_{B 2} ;[010]_{B 19}\right\|[101]_{B 2} ;[001]_{B 19} \|[10 \overline{1}]_{B 2}$ plate " $C$ ":

$[100]_{B 19}\left\|[100]_{B 2} ;[010]_{B 19}\right\|[011]_{B 2} ;[001]_{B 19} \|[0 \overline{1} 1]_{B 2}$

Similar lattice correlations exist when comparing orientation of the $B 2$ parent phase and the martensite plates in grains, which was formed after first cooling cycle. From comparison of obtained results for the martensite plates orientation and these from Table II, it can be found that in the $\mathrm{Ni}_{25} \mathrm{Ti}_{50} \mathrm{Cu}_{25}$ ribbon following martensite variants are formed: 1,3 , and 5 . Such combination of the variants allows for compensation of deformation, which appears during transformation. Discussed case of one grain was representative to the rest of the grains in the $\mathrm{Ni}_{25} \mathrm{Ti}_{50} \mathrm{Cu}_{25}$ ribbon. Also, these variants were identified in other grains.

Another aspect of the martensite formation can be also discussed. In discussed grain, let us compare orientation of martensites formed before and after first thermal cycle. As it was previously stated - both orientations are the same. However, completely different shape of the martensitic plates is formed. In one grain of the "primary" martensite, the plates are formed in two directions: parallel (upper part of grain) as well as perpendicular (lower part of grain) to the length of the ribbon (Fig. 3a and c). In the martensite grain, formed after thermal cycling, all plates are wider and oriented perpendicularly to the length of the ribbon, only. It means that "secondary" martensite found arrangement of the martensite plates, which allows for better compensation of deformations associated to the martensitic transformation.

\section{Conclusions}

Obtained results can be summarized by drawing the following conclusions:

- Thermal cycling of the martensitic transformation causes shift of the characteristic temperatures (lowering of $A_{s}$ and $A_{f}$ temperatures) as a result of martensite stabilization.

- In the $\mathrm{Ni}_{25} \mathrm{Ti}_{50} \mathrm{Cu}_{25}$ ribbon, martensite plates are formed in variants: 1,3 , and 5 independently of thermal cycle.

- Thermal cycle done in the $\mathrm{Ni}_{25} \mathrm{Ti}_{50} \mathrm{Cu}_{25}$ ribbon caused rearrangement of the martensite plates without change of their orientation. 


\section{References}

[1] T.H. Nam, T. Saburi, Y. Nakata, K. Shimizu, Mater. Trans. JIM 31, 1050 (1990).

[2] F. Fukuda, T. Kakeshita, M. Kitayama, K. Saburi, J. Phys. IV 5, C8-717 (1995).

[3] M. Kapgan, K.N. Melton, Engineering Aspects of Shape Memory Alloys, Butterworth-Heinemann, London 1990.

[4] T.H. Nam, T. Saburi, K. Shimizu, Mater. Trans. JIM 31, 959 (1990).

[5] H. Sehitoglu, I. Karaman, X. Zhang, A. Viswanath, Y. Chumlyakov, H.J. Maier, Acta Mater. 49, 3621 (2001).
[6] T. Goryczka, P. Ochin, Solid State Phenom. 203204, 101 (2013).

[7] T. Goryczka, P. Ochin, J. Mater. Process. Technol. 162-163, 178 (2005).

[8] T. Goryczka, P. Ochin, Mater. Sci. Eng. A 438-440, 714 (2006).

[9] T.E. Wert, J.A. Buchheit, Metall. Mater. Trans. A 25, 2383 (1994).

[10] Y. Watanabe, T. Saburi, Y. Nakagawa, S. Nenno, J. Japan Inst. Metals (Nippon-kingokugakkai-shi) 54, 861 (1990) (in Japanese). 